\title{
Coverage and parental perceptions of influenza vaccination among parents of children aged 6 to 23 months in Hong Kong
}

\author{
Joseph TF Lau ${ }^{1,2,3^{*}}$, Phoenix KH Mo ${ }^{1,2}$, Yan Shan Cai ${ }^{4}$, Hi Yi Tsui ${ }^{1 \wedge}$ and Kai Chow Choi ${ }^{5}$
}

\begin{abstract}
Background: The impact of influenza on young children can be severe and even fatal. Influenza vaccination (IV) has been shown to be effective in reducing complications of influenza among children. This study investigated the prevalence and factors of IV among children aged 6-23 months in Hong Kong.

Methods: A sample of 401 Chinese parents of children aged 6-23 months were interviewed at local Maternal and Child Health Centers. Socio-demographic information, variables related to Health Belief Model, including perceptions about the child's chance of contracting influenza, perceived harm of influenza on children, perceived benefits and side-effects of IV, having received recommendations from health professionals to uptake IV, and IV behaviors of the children were measured. Multivariate analysis was used to examine factors associated with IV behaviors of children.

Results: Only 9\% of the children had ever been vaccinated. Among those parents who had heard of IV (92.0\%), substantial proportions perceived that IV could reduce the risk of influenza-induced complications (70.5\%),

hospitalization (70.5\%) and death (65.9\%). Relatively few of the participants believed that IV had no side effects (17.1\%) and even less had been recommended by health care professionals to uptake IV (10.6\%). Results from multivariate analysis showed that physician recommendations were associated with a higher likelihood for IV among younger children, whilst parental perceptions of the side effects of IV was associated with a lower likelihood for IV.

Conclusion: The prevalence of IV among children aged 6-23 months in Hong Kong was very low. Promotion of IV with the component of physician recommendations and parents' knowledge about IV safety for this group is warranted.
\end{abstract}

Keywords: Influenza vaccination, Parental perceptions, Children, Health belief model, Chinese

\section{Background}

The impact of influenza on young children can be severe and even fatal $[1,2]$. Although fatal cases from influenza infection among pediatric patients are rare, the prevalence of complications leading to hospitalization is quite high [3-5]. In Hong Kong, the adjusted rates of excess hospitalization for acute respiratory disease attributable to influenza were estimated to be 278.5 and 288.2 per 10,000 for children less than 1 year of age and 218.4 and

\footnotetext{
* Correspondence: jlau@cuhk.edu.hk

Deceased

'Centre for Health Behaviours Research, School of Public Health and Primary Care, Faculty of Medicine, The Chinese University of Hong Kong, Shatin,

Hong Kong SAR

${ }^{2}$ The Chinese University of Hong Kong Shenzhen Research Institute, Shenzhen, China

Full list of author information is available at the end of the article
}

209.3 per 10,000 for children 1 to less than 2 years of age in 1998 and 1999, respectively [6]. Many influenzaassociated hospitalizations could be avoided.

Influenza vaccination (IV) has shown to be effective in reducing influenza-related complications in different age groups [7-10], including pediatric patients [11]. Since 1994, the Hong Kong government has recommended elderly persons living in residential care homes, health care workers, poultry workers, persons aged 65 years or above, persons with a chronic illness, and children aged 6 to 23 months to take up IV [12,13]. The recommendation was later extended to children aged 6 to 59 months in 2010 [14] and adults aged 50 years old or above in 2012 [15]. Similar recommendations are found in other countries such as North America [16-19] and are also provided

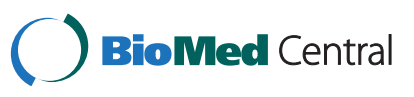


by other international health authorities, including the World Health Organization (WHO) [20].

Furthermore, since 2005 the Hong Kong government has provided free IV to children aged 6 to 23 months old of families receiving the Comprehensive Social Security Assistance (CSSA) [21]; it was further extended to children of age 6 to 59 months in 2010 [22]. In addition, since 2008, the government has launched the Childhood Influenza Vaccination Subsidy Scheme (CIVSS) to subsidize all children aged 6-59 months old to take up IV from private practitioners. The subsidy was increased from HK\$80 (US\$10) to HK\$130 (US\$16.5) per dose since September 24, 2012 [23], whilst the market rate for IV was about HK\$150-200 (US\$19.2 to US\$25.6).

Despite the recommendations and supportive policy, the prevalence of IV in different populations is low in Hong Kong. Population-based studies, in 2005, showed that $75.7 \%$ of respondents aged 18 to 64 in Hong Kong had never received an IV [24]. To our knowledge, there is no data on the prevalence of IV uptake among children aged 6 to 23 months old in Hong Kong. A number of western studies reported poor public awareness and misconceptions about infectivity and severity of influenza, as well as concerns over the safety of IV [25-28]. Studies showed that parental worry was an important intervening variable affecting uptake of and compliance with IV $[29,30]$. Similarly, studies have reported much worry among parents with respect to their children's risk for contracting SARS and avian flu [31-33]. Therefore, investigation of parental perceptions on IV is required for understanding vaccination coverage among children.

A number of western studies examined factors associated with IV among elderly [34-37] and other populations, such as adults with asthma [38] or healthcare workers [39], but relatively few of these studies targeted young children [40-42]. Similarly in Hong Kong, most of the studies on IV focused on the elderly population [43-46]. Despite the high influenza-related morbidity rate among young children, relatively few studies investigated IV in the 6-23 month old age group and most of these studies were conducted in the United States [47]. As Hong Kong has a higher population density and worse air pollution compared to the United States, it is expected that the prevalence of IV and associated factors among young children would be different. To our knowledge, no similar studies have ever been conducted for the 6 to 23 month old children in Chinese populations.

This study investigated the prevalence of IV, the prevalence of completing the follow-up IV within one month after getting the first IV shot in one's lifetime and the prevalence of parental behavioral intention for having the child take up IV in the coming 12 months. Among those parents who had heard of IV, we investigated factors associated with IV (i.e. having ever taken up IV, having taken up IV in 2005/2006 flu season, inclination to have the child take up IV in the coming 12 months) amongst the index child aged 6-23 months. The Health Belief Model (HBM) has been commonly used to identify potential determinants of IV [29,45,48-51]. In the present study, parental perceptions, with respect to influenza and IV for the index child aged 6-23 months, were gauged based on some constructs of the HBM: perceived susceptibility of influenza, perceived severity of influenza, perceived benefits of IV, perceived barriers of IV, and cues to action for IV. In addition, descriptions with respect to health services seeking behaviors in the last episode of influenza, reasons for taking up or not taking up IV, occurrences of any side-effects for the last episode of IV, and incompletion of the second dose were reported.

\section{Methods}

\section{Study population and sampling}

The study population comprised of the Chinese father or mother of a child aged 6 to 23 months old, who utilized the services in one of the ten randomly selected Maternal and Child Health Centres (MCHCs) in Hong Kong (out of a total of $31 \mathrm{MCHCs}$ ). The MCHCs in Hong Kong are public health centers of the Department of Health offering health services to mothers or children under the age of 11 . All local children of that age range can receive child health services and pneumococcal vaccination MCHCs free of charge. In 2009 , about $74 \%$ of all local newborns had received free services from MCHCs [52]. The study was conducted during May to June, 2006. Research assistants were trained as fieldworkers for the study. Using convenience sampling methods, either the father or the mother (but not both), was invited to join the study while they were waiting to receive services in the MCHCs during the research period. In the waiting hall, prospective respondents were approached and were briefed by these well-trained fieldworkers and were invited to join the study. Trained fieldworkers interviewed the eligible respondents in a private setting using an anonymous structured questionnaire. The face-to-face interview took about 15 minutes to complete. A total of 429 eligible prospective respondents were approached and 401 consented to take part. All of them completed the interview. The response rate, defined as the number of completed interviews divided by the number of eligible respondents being invited to join the study, was hence $93.5 \%$. Verbal informed consent was obtained from the respondents before the interviews commenced. The interviewers signed a form explaining the details of the study to the respondents. Ethics approval was obtained from both the ethics committees at the Chinese University of Hong Kong and the Department of Health.

\section{Measures}

Respondents' socio-demographic information such as gender of the index child, age, education level, whether the household was receiving CSSA, and residential district 
was collected. Based on the HBM, perceptions including perceived susceptibility (i.e. chance of contracting influenza by children aged 6 to 23 months old compared to the general public) and perceived severity of influenza (i.e. severity of influenza in the index child and in children aged 6 to 23 months compared to the general public), perceived benefits (i.e. reduction of influenza-induced complications, hospitalization and fatality) and perceived barriers of IV (i.e. perceived side effects of IV), and cues to action (i.e. ever receiving recommendations from healthcare professionals to uptake IV and awareness of governmental recommendations for children aged 6-23 months to take up IV) were assessed by items that were constructed for this study.

Information related to IV, such as whether the participants had ever heard of IV, whether the index child had ever taken up IV and whether a follow-up second dose at one month was received after taking up the first IV shot in the child's lifetime were recorded. Additional information documented included the inclination to have the child take up IV in the coming 12 months as well as conditions that would facilitate such a behavior in the coming 12 months. Other information related to the last episode of IV including the venue of vaccination, the most important reason for the child having or not having taken up IV, completing the 2-dose course at one month after taking up the first IV in the child's lifetime, and side effects as well as the nature of the side effects, if any, was reported. Health services seeking behaviors with respect to the child's last episode of influenza and the maximum amount of money that the parent was willing to pay for IV to reduce the child's risk of contracting IV was also recorded.

\section{Statistical analysis}

Descriptive statistics were presented. There were three dependent variables: 1) having ever taken up IV; 2) having taken up IV since the end of the last flu season (September 2005); and 3) inclination to have the child take up IV in the coming 12 months. The independent variables included all the socio-demographic variables (listed in Table 1), the HBM variables (listed in Table 2), and willingness to pay variable (listed in Table 2). As some potential factors related to perceptions of IV, only those respondents who reported having had heard of IV were included in the logistic regression analyses. To identify factors associated with the dependent variables, univariate logistic regression analyses were performed first and resulting univariate odds ratios $(\mathrm{ORu})$ were presented. We then used those factors that were significant in the univariate analyses as candidates for multivariate stepwise logistic regression analyses to derive multivariate odds ratios $\left(\mathrm{OR}_{\mathrm{m}}\right)$ and respective $95 \%$ confidence intervals $(\mathrm{CI})$; a set of significant independent variables was hence selected by that model. All statistical analyses were performed using SPSS for Windows 14.0 and a pvalue of $<0.05$ was taken as statistically significant.

\section{Results}

\section{Background characteristics}

Of all respondents, $84.8 \%$ were mothers, $81.0 \%$ were aged 25 to $39 ; 27.7 \%$ had attained an education level of postsecondary school or above; $2.5 \%$ were receiving CSSA (Table 1). Of the index children, $45.0 \%$ were female.

\section{Perceived susceptibility and severity of influenza}

Of all respondents, $50.8 \%$ perceived very severe or severe health impacts on the index child if the child was to contract influenza; $61.6 \%$ perceived influenza to have more severe or much more severe health consequences on children aged 6 to 23 months old than on the general public; $57.6 \%$ perceived children aged 6 to 23 months old to have higher or much higher chances of contracting influenza as compared to the general public (Table 1).

\section{Prevalence and perceptions related to IV}

Of all the respondents, $92.0 \%$ had heard of IV. However, only $9.0 \%$ of all index children had ever taken up IV, and $8.5 \%$ of all index children had done so during the 2005/06 flu season (Table 1). Of all the respondents, a total of 151 planned to have their index child receive IV in the coming 12 months (40.9\% for parents who had heard of IV).

Of those who had heard of IV (92\% of all respondents), similar proportions perceived that IV could reduce the risk of influenza-induced complications (70.5\%) and hospitalization (70.5\%); $65.9 \%$ perceived that IV could reduce the risk of death due to influenza; $88.1 \%$ believed that IV could reduce at least one of the three types of complications (perceived benefit). However, significant proportions of the respondents chose the "don't know" answer (13.6\% to $16.3 \%)$ for such questions. It is important to point out that only a minority of the respondents (17.1\%) perceived that IV had no side effects on children aged 6 to 23 months old (perceived barrier). With respect to cues to action, only $10.6 \%$ of the respondents had been recommended by some health care professionals to vaccinate their child whereas $68.8 \%$ of them were not aware of the governmental recommendations regarding the uptake of IV in children aged 6 to 23 months old. More than a quarter $(27.9 \%)$ of the respondents were willing to pay over HK\$300 (approx. US\$38.68), while $44.2 \%$ were willing to pay HK\$1-150 (approx. US\$0.1319.34) to obtain some benefits (such as reduction of the risk of influenza-induced complications/hospitalization) from their index child being vaccinated (Table 2).

Concerning descriptions on facilitating conditions, substantial proportions of the respondents believed that recommendations provided by health care professionals 
Table 1 Background characteristics of all respondents $(\mathrm{N}=401)$

\begin{tabular}{lll}
\hline $\mathbf{n}$ & $\%^{\#}$ \\
\hline
\end{tabular}

\section{Socio-demographic factors}

Gender

$$
\begin{aligned}
& \text { Male } \\
& \text { Female } \\
& 18-19 \\
& 20-24 \\
& 25-29 \\
& 30-34 \\
& 35-39 \\
& 40-44 \\
& 45-49 \\
& 50-54
\end{aligned}
$$$$
\text { Age }
$$

Education level

Primary school or below

Junior - senior secondary school

Post secondary or matriculation

University or above

340

61

340

2

24

74

159

92

92

44

4

2

19

19

271

32

79

Receiving CSSA

Yes

No

Refused to answer

Gender of the index children

$$
\text { Male }
$$

Female

Age of the index children

6 months to 12 months

13 months to 23 months

\section{Information related to influenza}

Perceived health impact on own child if contracting influenza (perceived severity)

Very severe/Severe
Moderate
Mild
No effect
Do not know

Perceived consequences of contracting influenza in children aged 6-23 months compared to the general public (perceived severity)

Much more severe/More severe
Same
Less severe/Much less severe

\section{Table 1 Background characteristics of all respondents ( $\mathbf{N}=\mathbf{4 0 1}$ ) (Continued)}

Perceived chances for children aged 6-23 months to contract influenza compared to the general public (perceived susceptibility)

\begin{tabular}{lcc} 
Much higher/Higher & 231 & 57.6 \\
Same & 122 & 30.4 \\
Lower/Much lower & 47 & 11.7 \\
Do not know & 1 & 0.2 \\
Ever heard of IV & 369 & 92.0 \\
Ever had IV & 36 & 9.0 \\
Received IV in the 05/06 flu season & 34 & 8.5 \\
Age of the index children at the last IV & & \\
6 months to 12 months & 16 & 47.1 \\
13 months to 21 months & 18 & 52.9 \\
Health service seeking behaviors for & & \\
the last influenza & & \\
Visited private clinics & 233 & 57.2 \\
Visited government/HA general & & 10.3 \\
outpatient clinics & 42 & \\
Took herbal medicine & & 2.5 \\
Visited acute and emergency unit & 10 & 2.0 \\
Took over-the-counter western medicine & 8 & 1.5 \\
Saw a traditional Chinese & 6.2 \\
medicine (TCM) doctor & 6 & 0.2 \\
Took over-the-counter TCM & 2 & 0.5 \\
No treatment/No drugs used & & \\
Do not know & & \\
Not ever having influenza & 5 & 1.2 \\
\hline
\end{tabular}

"Valid percentages were reported (i.e. missing values were not included in the denominator) and the frequencies therefore may not sum up to the total.

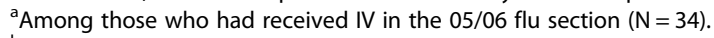

${ }^{\mathrm{b}}$ Among those who had had influenza $(\mathrm{N}=302)$. Multiple answers were allowed, so summing up the individual numbers ( $\mathrm{n}$ ) might not be equal to the total number of respondents $(\mathrm{N})$ in each sample.

(90.2\%), suggestions given by one's family members (72.6\%), the reporting of a new human case of avian flu in

Hong Kong (65.3\%) and proximity to a venue providing IV services (64.8\%) would increase the index child's likelihood for taking up IV (Table 1).

\section{Facts related to the last episode of IV}

Among those index children who had received IV during the $2005 / 06$ flu season $(\mathrm{N}=34), 64.7 \%$ took up the IV in private clinics, $11.8 \%$ in MCHCs and $2.9 \%$ in governmental clinics. The most important reasons mentioned to account for this episode of IV included: "influenza prevention" (47.1\%), "worry about the child contracting influenza/avian influenza" (32.3\%), "being recommended by health care professionals" (14.7\%), and "influenced by peer/family" (2.9\%). Five (15\%) respondents reported their index child had had some side effects associated with his/ 
Table 2 Perceptions related to influenza and influenza vaccination (IV) and facilitating conditions related to IV among parents of young children who had heard of IV ( $\mathbf{N}=\mathbf{3 6 9})$

\section{Perceptions related to influenza and IV}

n $\%^{\#}$

Perceived chances for children aged 6-23 months to contract influenza compared to the general public (perceived susceptibility)

Much higher/Higher
Same
Lower/Much lower
Perceived health impact on own child if
contracting influenza (perceived severity)

contracting influenza (perceived severity)

Very severe/Severe
Moderate
Mild
No effect
Do not know

Perceived consequences of contracting influenza in children aged 6-23 months compared to the general public (perceived severity)

Much more severe/More severe

Perceived benefit of IV in reducing risk of influenza-induced complications, e.g. pneumonia (perceived benefit)

$$
\begin{aligned}
& \text { Yes } \\
& \text { No }
\end{aligned}
$$$$
\text { Do not know }
$$

Perceived benefit of IV in reducing risk of hospitalization due to influenza (perceived benefit)

Yes

No

Do not know

Perceived benefit of IV in reducing risk of death due to influenza (perceived benefit)

$$
\begin{aligned}
& \text { Yes } \\
& \text { No } \\
& \text { Do not know }
\end{aligned}
$$

Perceived benefit of IV in reducing at least one of the three above types of complications (perceived benefit)

$$
\begin{aligned}
& \text { Yes } \\
& \text { No }
\end{aligned}
$$

Perceived side effects of IV (perceived barrier)

No side effect

Not severe

Severe

Do not know

No

$39 \quad 10.6$

Awareness of governmental recommendation on children aged 6-23 months to take up IV (cue to action)

$\begin{array}{lll}\text { Yes } & 115 & 31.2 \\ \text { No } & 152 & 41.2 \\ \text { Do not know } & 102 & 27.6\end{array}$

Inclined to have the child taking up IV in the coming 12 months

$\begin{array}{lll}\text { Yes } & 151 & 40.9 \\ \text { No } & 116 & 31.4 \\ \text { Do not know } & 102 & 27.6\end{array}$

The largest amount willing to pay for IV which could effectively reduce the risk of influenza-induced complications/hospitalization (in HKȘ)

$\begin{array}{lcc}0 & 36 & 9.8 \\ 1-150 & 127 & 34.4 \\ 151-300 & 103 & 27.9 \\ 301-500 & 61 & 16.5 \\ 501-1000 & 22 & 6.0 \\ >1000 & 20 & 5.4\end{array}$

\section{Facilitating conditions of IV}

More likely to be vaccinated if IV is to be provided proximal to residence

$\begin{array}{lcc}\text { Yes } & 239 & 64.8 \\ \text { No } & 103 & 27.9 \\ \text { Do not know } & 27 & 7.3 \\ \text { More likely to be vaccinated if supported by family } & & \\ \text { Yes } & 268 & 72.6 \\ \text { No } & 77 & 20.9 \\ \text { Do not know } & 24 & 6.5\end{array}$

More likely to be vaccinated if recommended

by health care professionals

$\begin{array}{lcc}\text { Yes } & 333 & 90.2 \\ \text { No } & 23 & 6.2 \\ \text { Do not know } & 13 & 3.5\end{array}$

More likely to be vaccinated if there is a new human case of avian flu in Hong Kong

\begin{tabular}{lcc} 
Yes & 241 & 65.3 \\
No & 96 & 26.0 \\
Do not know & 32 & 8.7 \\
\hline
\end{tabular}

"Valid percentages were reported (i.e. missing values were not included in the denominator) and the frequencies therefore may not sum up to the total. ${ }^{\mathrm{a}} \mathrm{HK} \$ 1=$ US\$ 0.13 .

Table 2 Perceptions related to influenza and influenza vaccination (IV) and facilitating conditions related to IV among parents of young children who had heard of IV ( $\mathbf{N}=\mathbf{3 6 9})$ (Continued)

2 . 
her last episode of IV during the 2005/06 flu season. Fever was the only side effect that was being mentioned $(\mathrm{N}=4)$ (Table 3).

"Not necessary" (23.2\%), "do not know/had not thought about it" (11.4\%), "the child is in good health condition" (10.7\%), "the baby is too young" (10.0\%), "had not been recommended by health care professionals" $(8.8 \%)$ and "worry about side effects of IV" (8.1\%) were the most commonly given reasons to explain why the index child had never taken up IV or did not take up IV during the 2005/ 06 flu season. Other reasons were presented in Table 3.

\section{Compliance with the recommendations for 2 doses of influenza vaccine in the index children first vaccinated} Among a total of 36 children having previously been vaccinated, 12 (33.3\%) had only taken up one shot of IV in their lifetime (i.e., without taking up the required second dose, which should be within an one month interval). The most important reasons for not completing the 2dose course of IV included: "did not realize that a followup dose was required" $(n=4)$, "out of stock" $(n=2)$, "the child was sick" $(n=2)$, and other reasons $(n=4)$. All the remaining 24 children (66.7\%) had received the follow-up IV after receiving the first lifetime IV shot (Table 4).

\section{Factors associated with adoption of IV}

For all three dependent variables, none of the background variables listed in Table 1 were found to be statistically significant in the univariate analyses. As mentioned in the section in Statistical Analysis, these variables were hence not considered in the subsequent multivariate analyses.

The results of the multivariate analyses showed that variables for cues to action, including recommendations provided by health care professionals that the index child should take up IV (multivariate OR $=17.65, \mathrm{p}<0.01$ ) and awareness of the governmental recommendation that children aged 6 to 23 months old should take up IV (multivariate $\mathrm{OR}=2.81, \mathrm{p}<0.05$ ) were associated with the index child getting the IV sometime during their lifetime. Lower likelihood for ever taking up IV was found for variables on perceived side effects induced by IV (multivariate OR = $0.17, \mathrm{p}<0.01$ ) and uncertainty about whether IV has some side effects (multivariate $\mathrm{OR}=0.06, \mathrm{p}<0.01$ ) (Table 5).

Similar multivariate analysis showed that recommendations provided by health care professionals, that the index child should take up IV, (multivariate OR $=17.28$, $\mathrm{p}<0.01$ ) were associated with the index child's experience when they received the IV during the 2005/06 flu season. Similarly, the reverse was true that perceived IVinduced side effects (multivariate $\mathrm{OR}=0.16, \mathrm{p}<0.01$ ) and uncertainty about the presence of such side effects (multivariate $\mathrm{OR}=0.06, \mathrm{p}<0.01$ ) were associated with lower likelihood of vaccination during the 2005/06 flu season. Awareness of the government's recommendation that children aged 6 to 23 months should take up IV was significant in the univariate but not in the multivariate analysis (Table 5).

Furthermore, the perceived benefit of IV in reducing the risk of influenza-induced complications, hospitalization or death (multivariate $\mathrm{OR}=3.20, \mathrm{p}<0.05$ ), perceived severity of a potentially severe/very severe negative health impact of influenza onto the index children (multivariate $\mathrm{OR}=$ $2.69, \mathrm{p}<0.05)$, and cue to action represented by recommendations provided by health care professionals that the index child should take up IV (multivariate OR $=2.31$, $\mathrm{p}<0.05$ ) were associated with parental inclination towards having their index children take up IV in the coming 12 months. Significant associations in the opposite direction were found for variables including perceived side effects of IV (multivariate OR $=0.51, \mathrm{p}<0.05$ ) and uncertainty about the presence of such side effects (multivariate $\mathrm{OR}=0.37, \mathrm{p}<0.01)$. Willingness to pay for the benefits of IV in reducing risk for influenza-induced complications/ hospitalization and awareness of the governmental recommendation for children aged 6 to 23 months old were of statistical significance in the univariate but not in the multivariate analysis (Table 5).

\section{Health service seeking behaviors for the index Child's last episode of influenza}

The model health service seeking behaviors during the index child's last episode of influenza was visiting private doctors $(57.2 \%)$, followed by visiting governmental clinics (10.3\%). Other much less frequently mentioned options included using herbal medicine (2.5\%), visiting Acute and Emergency Unit (2.0\%), using over-the-counter western medicine $(1.5 \%)$, seeing a traditional Chinese medicine (TCM) doctor $(0.5 \%)$, and using over-the-counter TCM $(0.2 \%)$. Only a few of all the respondents refused to seek any treatment, or use any drugs $(1.2 \%)$ during that last episode of influenza suffered by the index child (Table 1).

\section{Discussion}

We found that only $9 \%$ of the children aged 6 to 23 months old had ever received IV (8.5\% in the 2005/06 flu season). This prevalence is far lower than the $32.2 \%$ prevalence of IV reported for the same age group in the United States in 2005 [39]. Among the children who have ever received IV, the majority of them received the IV in the 2005/06 season. Since about half of the children were below the age of 12 months at the survey date, it is conceivable that they could only receive IV in the current season. We also found that about two thirds of the parents were not aware of the governmental recommendation regarding IV for children aged 6 to 23 months and $8 \%$ of them had not even heard of IV. Therefore, promotion of IV targeting parents of this age group is urgently needed. 
Table 3 Information related to influenza vaccination (IV) since September 2005 (i.e., in the 05/06 flu season)

Place where the last episode of IV was received ${ }^{\text {a }}$
Private clinics
Maternal and Child Health Centres
School
Outside Hong Kong
Home
Government/HA general outpatient clinics
The most important reason of IV uptake
(last episode)
Prevent influenza
Worried about contracting influenza/avian influenz
Recommended by health care professional
Influence by peer/family
Others

Self-reported side effects (last episode of IV) ${ }^{a}$

Yes

No

Perceived types of side effect, if any (last episode of IV) $^{\mathrm{a}}$ b

Fever

Cannot remember/do not know

The most important reason of not uptaking IV

Not necessary

Do not know/had not thought about it

Good health conditions

Baby is too young

Had not been recommended by health care professional

Worried about side effects of IV

Out of stock

Afraid of clashing with other injections

Perceived that IV was not efficacious

Seldom go out

Did not know where to get IV

Sick

Not living in Hong Kong

Busy

Fear of too many injections required

Did not want to uptake IV

Perceived that the IV taken more than 6 months ago was still efficacioius

Cannot afford it

n ${ }^{\#}$

Table 3 Information related to influenza vaccination (IV) since September 2005 (i.e., in the 05/06 flu season) (Continued)

\begin{tabular}{|c|c|c|}
\hline Allergic to IV & 3 & 0.7 \\
\hline Inadequate knowledge about IV & 3 & 0.7 \\
\hline No reason given & 2 & 0.5 \\
\hline Others (e.g., need to inject twice, etc.) & 13 & 3 \\
\hline \multicolumn{3}{|c|}{$\begin{array}{l}\text { \#Valid percentages were reported (i.e. missing values were not included in the } \\
\text { denominator) and the frequencies therefore may not sum up to the total. } \\
{ }^{a} \text { Among children aged } 6-23 \text { months who had taken up IV since September } \\
2005(\mathrm{~N}=34) \text {. } \\
{ }^{b} \text { Multiple answers were allowed, so summing up the individual numbers }(\mathrm{n}) \\
\text { might not be equal to the total number of respondents }(\mathrm{N}) \text { in each sample. } \\
{ }^{c} \text { Among children aged } 6-23 \text { months who had not yet taken IV or not uptake IV } \\
\text { since September } 2005(\mathrm{~N}=335) \text {. }\end{array}$} \\
\hline
\end{tabular}

Among parents who chose not to have their child vaccinated, the most common reasons mentioned were that parents believed it to be "unnecessary", "the child is in good health condition" and "the baby is too young". This is consistent with other study findings that there is a lack of parental awareness about the importance of IV among healthy young children, children with chronic health conditions, and children in close contact with high-risk individuals [42,53-55]. In addition, a significant proportion of the parents gave "don't know" answers to IV related knowledge. Together, these results suggest a need to increase parental education about influenza disease and IV. Multiple communication strategies including

Table 4 Prevalence of fully vaccinated with influenza vaccine (IV) among children aged 6-23 months who ever had received IV $(N=36)$

n $\quad \%^{\#}$

The last episode of IV was:

a). The first shot in life

No follow-on second dose received $\quad 12^{\mathrm{a}} \quad 33.3$

Follow-on second dose received

$0 \quad 0$

b). Not the first shot in life

Being the second dose $24^{\mathrm{b}} \quad 66.7$

Not being the second dose

0

The most important reason for not having the second dose of IV

Did not realize a second dose of IV was required

Out of stock

Sick

Others denominator) and the frequencies therefore may not sum up to the total. ${ }^{a}$ All 12 children received the last IV in the 2005/06 flu season except one.

${ }^{b}$ All 24 children received the last IV in the 2005/06 flu season except one. 'Among those who received the first IV shot in life but not the follow-on second dose $(\mathrm{N}=12)$. 
Table 5 Predictors of influenza vaccination (IV) behaviors among parents of children aged 6 to 23 months who had heard of IV ( $N=369$ )

\begin{tabular}{|c|c|c|c|c|c|c|c|c|c|}
\hline & \multicolumn{3}{|c|}{ Ever had influenza vaccination } & \multicolumn{3}{|c|}{ Vaccinated since September 2005} & \multicolumn{3}{|c|}{ Inclined to be vaccinated in the next year } \\
\hline & Row\%" & $\mathrm{OR}_{\mathrm{u}}$ & $\mathrm{OR}_{\mathrm{m}}(95 \% \mathrm{Cl})$ & Row\%" & $\mathrm{OR}_{\mathrm{u}}$ & $\mathrm{OR}_{\mathrm{m}}(95 \% \mathrm{Cl})$ & Row\%" & $\mathrm{OR}_{\mathrm{u}}$ & $\mathrm{OR}_{\mathrm{m}}(95 \% \mathrm{Cl})$ \\
\hline \multicolumn{10}{|c|}{ Perceived chances for children aged 6-23 months to contract influenza as compared to the general public (perceived susceptibility) } \\
\hline Much lower/lower/same & 7.7 & 1.00 & & 7.7 & 1.00 & & 38.7 & 1.00 & \\
\hline Higher/much higher & 11.2 & 1.51 & NA & 10.3 & 1.37 & NA & 42.5 & 1.17 & NA \\
\hline \multicolumn{10}{|c|}{ Perceived health impact on own child if contracting influenza (perceived severity) } \\
\hline No effect/mild & 2.9 & 1.00 & & 2.9 & 1.00 & & 26.5 & 1.00 & 1.00 \\
\hline Moderate & 7.0 & 2.50 & & 7.0 & 2.50 & & 26.1 & 0.98 & $0.75(0.30-1.85)$ \\
\hline Severe/very severe & 13.0 & 4.91 & NA & 11.9 & 4.46 & NA & 54.4 & $3.31^{* *}$ & $2.69(1.13-6.42)^{*}$ \\
\hline \multicolumn{10}{|c|}{$\begin{array}{l}\text { Perceived consequences of contracting influenza in children aged 6-23 months compared to the general } \\
\text { public (perceived severity) }\end{array}$} \\
\hline Much less severe/less severe/same & 8.0 & 1.00 & & 8.0 & 1.00 & & 35.0 & 1.00 & \\
\hline Much more severe/much severe & 10.8 & 1.38 & NA & 9.9 & 1.26 & NA & 44.4 & 1.48 & NA \\
\hline \multicolumn{10}{|c|}{$\begin{array}{l}\text { Perceived benefits of IV in reducing at least risk of influenza-induced complications, hospitalization or } \\
\text { death (perceived benefits) }\end{array}$} \\
\hline Else & 6.8 & 1.00 & & 6.8 & 1.00 & & 15.9 & 1.00 & 1.00 \\
\hline Yes & 10.2 & 1.55 & NA & 9.5 & 1.44 & NA & 44.3 & $4.21 *$ & $3.20(1.29-7.93)^{*}$ \\
\hline \multicolumn{10}{|c|}{ Perceived side effects of IV (perceived barrier) } \\
\hline No & 31.7 & 1.00 & 1.00 & 31.7 & 1.00 & 1.00 & 61.9 & 1.00 & 1.00 \\
\hline Yes & 7.2 & $0.17^{* *}$ & $0.17(0.06-0.43)^{* *}$ & 6.1 & $0.14^{* *}$ & $0.16(0.06-0.40)^{* *}$ & 38.9 & $0.39^{* *}$ & $0.51(0.27-0.98)^{*}$ \\
\hline Do not know & 2.4 & $0.05^{* *}$ & $0.06(0.01-0.24)^{* *}$ & 2.4 & $0.05^{* *}$ & $0.06(0.02-0.25)^{* *}$ & 33.3 & $0.31^{* *}$ & $0.37(0.18-0.74)^{* *}$ \\
\hline \multicolumn{10}{|c|}{ Recommendation from healthcare professionals to uptake IV (cue to action) } \\
\hline No & 4.5 & 1.00 & 1.00 & 4.5 & 1.00 & 1.00 & 37.9 & 1.00 & 1.00 \\
\hline Yes & 53.8 & $24.50 * *$ & $17.65(7.10-43.89)^{* *}$ & 48.7 & $19.95^{* *}$ & $17.28(6.97-42.83)^{* *}$ & 66.7 & $3.28 * *$ & $2.31(1.04-5.12)^{*}$ \\
\hline \multicolumn{10}{|c|}{ Awareness of Government's recommendation on children aged 6-23 months to uptake IV(cue to action) } \\
\hline No & 6.6 & 1.00 & 1.00 & 6.6 & 1.00 & & 37.5 & 1.00 & \\
\hline Yes & 19.1 & $3.36 * *$ & $2.81(1.03-7.67)^{*}$ & 17.4 & $2.99^{* *}$ & & 53.9 & $1.95^{* *}$ & \\
\hline Do not know & 3.9 & 0.58 & $0.83(0.20-3.42)$ & 3.9 & 0.58 & NS & 31.4 & 0.76 & NS \\
\hline
\end{tabular}


Table 5 Predictors of influenza vaccination (IV) behaviors among parents of children aged 6 to 23 months who had heard of IV ( $N=369$ ) (Continued) The largest amount willing to pay for IV (HK\$) $)^{a}$

$\begin{array}{lcc}0 & 2.8 & 1.00 \\ 1-150 & 11.0 & 4.34 \\ 151-300 & 9.7 & 3.76 \\ >300 & 10.7 & 4.18\end{array}$

"Valid percentages were reported (i.e. missing values were not included in the denominator) and the frequencies therefore may not sum up to the total.

${ }^{*}-\mathrm{p}<0.05 ;{ }^{* *}-\mathrm{p}<0.01 ; \mathrm{OR}_{\mathrm{u}}$ - univariate odds ratio; $\mathrm{OR}_{\mathrm{m}}$ - multivariate odds ratio obtained from multivariate stepwise logistic regression; NA: not chosen for multivariate logistic regression analyses as the factor was $*-\mathrm{p}<0.05 ; * *-\mathrm{p}<0.01 ; \mathrm{OR}_{\mathrm{u}}$ - univariate odds ratio; $\mathrm{OR}_{\mathrm{m}}$ - multivariate odds ratio obtained from multivariate stepwise logistic regression; $\mathrm{NA}$ : not chosen for multivariate logistic regression analyses as the fatis
statistically non-significant in the univariate logistic regression analysis; NS: not statistically significant in the multivariate logistic regression. Variables that were significant in the $\mathrm{p}<0.05$ level were bolded. ${ }^{\mathrm{a} H K \$ 1}=$ US\$ 0.13 
media broadcasts, video, internet, telephone hotlines, and written information should be utilized [56-58].

In the logistic regression analyses, perceived benefits of IV and perceived severity of influenza were associated with a higher likelihood of IV, while perceived side effects of IV were associated with a lower likelihood of IV. Such findings supported the predictability of the HBM on IV in different age groups, including those of 6 to 23 months old [25,41]. Findings suggest that in addition to increasing awareness and knowledge about IV, interventions are warranted to improve cognitions on IV among parents of young children. The severity of influenza and efficacy of IV in reducing influenza should be highlighted. Misconceptions about side effects of IV in young children should also be mitigated.

Corroborating with the results of other studies, a doctor's recommendation, which can be seen as a cue to action, was an important factor associated with IV status and inclinations $[26,27,41,42,59,60]$. However, only a minority of parents in this study had ever received recommendations from a health care professional. There is certainly a strong need to increase the awareness and motivation of healthcare professionals in recommending IV to parents of young children. As the majority of the participants in the present study visited private clinics during the last episode of IV, private doctors should be mobilized to play a more important role in promoting IV among young children of 6-23 months old or in other age groups. Interventions should be designed to inform the doctors about the evidence based benefits of IV to relay to their patients and make doctors recognize the strong influence they have on parental decision on having their children vaccinated. However, there are some potential barriers. In a study conducted in the U.S., only $50 \%$ of pediatricians and $40 \%$ of family physicians considered it is possible to give suggestions on regular IV for children aged 6 through 35 months old; cost (77\%), vaccine safety issues $(52 \%)$, and the inability to identify eligible children (46\%) were frequently cited as other important potential barriers for recommending IV to parents of young children [61]. Future studies should address such issues. Randomized clinical trials on different ways to empower physicians to give recommendations about IV to parents of young children are greatly warranted.

It is also important to point out that $72.6 \%$ considered family support as a facilitating condition for having the child take up IV. Interventions should therefore be extended from parents and physicians to family members. Family members are important people to parents of young children. According to the Theory of Planned Behavior, subjective norm is defined as support obtained from significant others for performing a health-related behavior. It is an important determinant of behavioral intention which in turn determines the performance of the actual behavior
[62-65]. The theory has been used in explaining many health-related behaviors [35] but not frequently used to explain decisions on IV $[25,66]$. Health promotion should therefore also encourage family members to reinforce parents of young children to take up IV. Future studies should also compare different types of behavioral health theories, such as the HBM and TPB in predicting IV in this and other populations and use such results to plan for relevant health promotion.

Furthermore, $64.8 \%$ of the respondents reported proximity to sites offering IV service as a facilitating condition. Inconvenience can be seen as another perceived barrier of the HBM. Almost all private clinics in Hong Kong provide IV services and currently, the subsidy is close to the market rate. Such information should be provided to parents to inform them about proximal clinics that they may visit to seek IV services.

It is known that children aged of 6 months to 8 years who have never been vaccinated previously require two doses of trivalent influenza vaccine separated in time by $>$ 4 weeks to induce an optimal serum antibody response. A study assessing protective antibody responses after one and two doses of vaccine among children aged 5 to 8 years, who had never received the IV previously, indicated that children who received two doses were substantially more likely than those who received one dose to have a protective antibody response [67]. Another study found that no vaccine effectiveness was identified with partial vaccination among children who were aged 6 to 23 months, affirming that children need to be fully vaccinated to obtain the protective effects [68]. In this study, we have a small number of children who have previously taken up IV $(\mathrm{N}=36)$, but it is alarming that one-third of them were only partially vaccinated. This finding suggests that children of this age group do not benefit from IV, not only because of the low prevalence of IV but furthermore, by the even lower prevalence of full vaccination with two doses. Therefore, the need for increased measures to improve the proportion of children who are fully vaccinated is underscored. We contend that the knowledge about ineffective partial vaccination is unknown to the parents because few of them had discussed with health care professionals about matters related to IV for their young children.

The study has a few limitations. First, respondents were recruited from MCHC. Since a large proportion of the target population visited $\mathrm{MCHC}$, we believe that the sample has good representativeness. Selection bias could, however, have been introduced due to convenience sampling although the response rate has been high. Second, parent-reported IV history has not been validated against medical records and may be subject to recall bias. However, other self-reported IV studies have been found to be valid [69-71]. Self-reported IV among adults, when compared with extraction from the medical record is both a 
sensitive and specific source of information [72] and could rapidly provide available information to guide government policy and program decisions. Third, items in the present study were not based on validated scales. However, there was no standardized scale for HBM and it is very common that researchers self-constructed the HBM items based on the studied behavior [73]. Similar self-constructed items have been used in other studies on IV $[69,74]$. Finally, family members' experiences with IV were not measured in the study. Future studies should investigate how such experiences would affect IV among young children. Lastly, the survey was completed in 2006 and the prevalence may have changed. The data however, serve as benchmarks for future comparisons to gauge any improvements have been made.

\section{Conclusions}

In conclusion, the prevalence of IV among children aged 6 to 23 months in Hong Kong is very low. The most important factors related to immunization were doctor recommendations and parental cognitions related to influenza and IV based on HBM. To encourage compliance with vaccination, multiple strategies should be utilized in the future, involving parents, doctors and family members. Future studies should focus on understanding factors predicting IV, such as longitudinal studies which can establish causality between factors and IV, and intervention studies (randomized clinical trials) targeting physicians (especially private doctor) to increase their recommendation to parents, as well as intervention studies targeting parents to increase prevalence of IV for children of 6 to 23 months old. Similar studies should also be extended to the population of children aged 24-59 months old as the current WHO recommendation also covers this older pediatric age group.

\section{Competing interest}

The authors declared that they have no competing interests.

\section{Authors' contributions}

$J L, Y C$ and $H T$ designed the study; KC and PM performed the data analysis; $J$, PM interpreted the data; JL, PM, HT drafted the article; $J$ approved the final article. All authors read and approved the final manuscript.

\section{Acknowledgements}

The authors would like to thank all respondents for their participation in the study. Thanks are extended to Dr. Doreen Au for her help in editing of the manuscript. The study was supported by the Department of Health, Hong Kong Special Administrative Region.

\footnotetext{
Author details

${ }^{1}$ Centre for Health Behaviours Research, School of Public Health and Primary Care, Faculty of Medicine, The Chinese University of Hong Kong, Shatin, Hong Kong SAR. ${ }^{2}$ The Chinese University of Hong Kong Shenzhen Research Institute, Shenzhen, China. ${ }^{3}$ Centre for Medical Anthropology and Behavioral Health, School of Sociology and Anthropology, Sun Yat-sen University, Guangzhou, China. ${ }^{4}$ Department of Planned Immunization, Guangzhou Center for Disease Control, Guangzhou, China. ${ }^{5}$ The Nethersole School of Nursing, The Chinese University of Hong Kong, Shatin, Hong Kong SAR.
}

Received: 19 February 2012 Accepted: 8 October 2013

Published: 30 October 2013

\section{References}

1. Bhat N, Wright JG, Broder KR, et al: Influenza-associated deaths among children in the United States, 2003-2004. N Engl J Med 2005, 353:2559-2567.

2. Neuzil KM, Yuwei Z, Griffin MR, et al: Burden of interpandemic influenza in children younger than 5 years: A 25-year prospective study. J Infect Dis 2002, 185:147-152.

3. Heikkinen $T$, Silvennoinen $H$, Peltola $V$, et al: Burden of influenza in children in the community. J Infect Dis 2004, 190:1369-1373.

4. Izurieta HS, Thompson WW, Kramarz $P$, et al: Influenza and the rates of hospitalization for respiratory disease among infants and young children. N Engl J Med 2000, 342:232-239.

5. Neuzil KM, Mellen BG, Wright PF, Mitchel EF, Griffin MR: The effect of influenza on hospitalizations, outpatient visits, and courses of antibiotics in children. N Engl J Med 2000, 342:225-231.

6. Chiu SS, Lau YL, Chan KH, Wong WHS, Peiris JSM: Influenza-related hospitalizations among children in Hong Kong. N Engl J Med 2002, 347:2097-2103.

7. Belshe RB, Nichol KL, Black SB, et al: Safety, efficacy, and effectiveness of live, attenuated, cold-adapted influenza vaccine in an indicated population aged 5-49 years. Clin Infect Dis 2004, 39:920-927.

8. Nichol KL: Efficacy and effectiveness of influenza vaccination. Vaccine 2008, 26(Suppl 4):D17-D22.

9. Vu T, Farish S, Jenkins M, Kelly $\mathrm{H}$ : A meta-analysis of effectiveness of influenza vaccine in persons aged 65 years and over living in the community. Vaccine 2002, 20:1831-1836.

10. Centers for Disease Control and Prevention: CDC's advisory committee on immunization practices (ACIP) recommends universal annual influenza vaccination. [Centers for Disease Control and Prevention website]. 2010. Available at: www.cdc. gov/media/pressrel/2010/r100224.htm. Accessed Sep 3, 2013.

11. Grossman SL, Linares MYR: Influenza vaccination in the pediatric population. Int Pediatr 2008, 23:128-131.

12. Centre for Health Protection: Influenza vaccination. Department of Health for Disease Prevention and Control. 2004. in DH SEB CD/8/27/6II.

13. Centre for Health Protection: Scientific committee on vaccine preventable diseases: Recommendations on influenza vaccination for the 2008/09 season. [Centre for Health Protection web site]. 2008. Available at: http:// www.chp.gov.hk/files/pdf/SC_Recommed\%202008_eng.pdf. Assessed April 17, 2009

14. Gov HK: Influenza vaccination urged for target groups. 2010. Available at: http://www.info.gov.hk/gia/general/201012/13/P201012130239.htm. [press release] Dec 13, 2010. Assessed June 27, 2013.

15. Centre for Health Protection: Recommendations on Seasonal Influenza Vaccination for the 2012/13 Season. 2011. Available at: http://www.chp.gov. hk/files/pdf/recommendations_on_seasonal_influenza_ vaccination_for_the_201213_season.pdf. [Centre for Health Protection web site]. 2011. Assessed June 27, 2013.

16. Centers for Disease Control and Prevention: Prevention and control of influenza: recommendations of the Advisory Committee on Immunization Practices (ACIP). MMWR 2007, 56(RR-6):1-54.

17. Public Health Agency of Canada: Statement on influenza vaccination for the 2008-2009 season, Canada Communicable Disease Report. 2008:34. (ACS-3). Health Canada. Available at: www.phac-aspc.gc.ca/publicat/ccdr-rmtc/ 08vol34/acs-3/index-eng.php. Assessed April 17, 2009.

18. Van Essen GA, Palache AM, Forleo E, Fedson DS: Influenza vaccination in 2000: recommendations and vaccine use in 50 developed and rapidly developing countries. Vaccine 2003, 21:1780-1785.

19. Centers for Disease Control and Prevention: Prevention and Control of influenza with vaccines: interim recommendations of the advisory committee on immunization practices (ACIP). 2013. [Centers for Disease Control and Prevention website]. 2013. Available at: www.cdc.gov/mmwr/preview/ mmwrhtml/mm6218a3.htm. Accessed Sep 3, 2013.

20. World Health Organization: Recommendations for the use of inactivated influenza vaccines and other preventive measures, Weekly Epidemiological Record. 2000:75281-75288.

21. Department of Health: Influenza vaccination programme for $2005 / 06$ [Department of Health web site]. 2005. Available at: http://www.dh.gov.hk/ english/press/2005/050914.html.

22. Gov HK: Vaccination programmes 2010/11 to be launched in November. [press release]. Sep 16, 2010. Available at: http://www.info.gov.hk/gia/general/ 201009/16/P201009160209.htm Accessed June 27, 2011. 
23. Centre for Health Protection: Childhood influenza vaccination subsidy scheme. 2013. [Centre for Health Protection web site]. 2013. Available at: http:// www.chp.gov.hk/en/view_content/17994.html. Accessed July 2, 2013.

24. Centre for Health Protection: Influenza vaccination. 2006. [Centre for Health Protection web site]. 2006. Available at: http://www.chp.gov.hk/en/data/4/ 10/280/195.html. Accessed July 2, 2013.

25. Daley MF, Crane LA, Chandramouli V, et al: Misperceptions about influenza vaccination among parents of healthy young children. Clin Pediatr 2007, 46:408-417.

26. Nowalk MP, Zimmerman RK, Lin CJ, et al: Parental perspectives on influenza immunization of children aged 6 to 23 months. Am J Prev Med 2005, 29:210-214

27. Gnanasekaran SK, Finkelstein JA, Hohman K, O'Brien M, Kruskal B, Lieu TA: Parental perspectives on influenza vaccination among children with asthma. Public Health Rep 2006, 121:181-188.

28. Bults M, Beaujean DJ, Richardus JH, van Steenbergen JE, Voeten HA: Pandemic influenza A (H1N1) vaccination in The Netherlands: parental reasoning underlying child vaccination choices. Vaccine 2011, 29:6226-6235.

29. Szilagyi PG, Rodewald LE, Savageau J, Yoos L, Doane C: Improving influenza vaccination rates in children with asthma: A test of a computerized reminder system and an analysis of factors predicting vaccination compliance. Pediatrics 1992, 90:871-875.

30. Setbon M, Raude J: Factors in vaccination intention against the pandemic influenza A/H1N1. Eur J Publ Health 2010, 20:490-494.

31. Chan SSC, Leung D, Chui $H$, et al: Parental response to child's isolation during the SARS outbreak. Ambul Pediatr 2007, 7:401-404.

32. Lau JTF, Kim JH, Tsui HY, Griffiths S: Perceptions related to bird-to-human avian influenza, influenza vaccination, and use of face mask. Infection 2008, 36:434-443.

33. Wong WCW, Chan KC, Tang HW, Lam MWH: The cycle fear: A qualitative study of SARS and its impacts on kindergarten parents one year after the outbreak. Hong Kong Pract 2007, 29:146-155.

34. Evans MR, Watson PA: Why do older people not get immunised against influenza?: a community survey. Vaccine 2003, 21:2421-2427.

35. Frick KD, Simonsick EM: SES, medicare coverage, and flu shot utilization among vulnerable women in the women's health and aging study. Ann N Y Acad Sci 1999, 896:493-496.

36. Xakellis GC: Predictors of influenza immunization in persons over age 65 . J Am Board Fam Pract 2005, 18:426-433.

37. Nagata JM, Hernández-Ramos I, Kurup AS, Albrecht D, Vivas-Torrealba C, Franco-Paredes C: Social determinants of health and seasonal influenza vaccination in adults $\geq 65$ years: a systematic review of qualitative and quantitative data. BMC Public Health 2013, 13:388.

38. Keenan $\mathrm{H}$, Campbell J, Evans PH: Influenza vaccination in patients with asthma: why is the uptake so low? Br J Gen Pract 2007, 57:359-563.

39. Prematunge C, Corace K, McCarthy A, Nair RC, Pugsley R, Garber G: Factors influencing pandemic influenza vaccination of healthcare workers-a systematic review. Vaccine 2012, 30:4733-4743.

40. Kramarz P, DeStefano F, Gargiullo PM, et al: Influenza vaccination in children with asthma in Health Maintenance Organizations. Vaccine 2000, 18:2288-2294.

41. Daley MF, Crane LA, Chandramouli V, et al: Influenza among healthy young children: changes in parental attitudes and predictors of immunization during the 2003 to 2004 influenza season. Pediatrics 2006, 117:e268-e277.

42. Offutt-Powell TN, Ojha RP, Qualls-Hampton R, Stonecipher S, Singh KP, Cardarelli KM: Parental risk perception and influenza vaccination of children in daycare centres. Epidemiol Infect 2013, 18:1-8.

43. Kwong EWY, Lam IOY, Chan TMF: What factors affect influenza vaccine uptake among community-dwelling older Chinese people in Hong Kong general outpatient clinics? J Clin Nurs 2009, 18:960-971.

44. Lau L, Lau Y, Lau YH: Prevalence and correlates of influenza vaccination among non-institutionalized elderly people: an exploratory crosssectional survey. Int J Nurs Stud 2009, 46:768-777.

45. Lau JTF, Kim JH, Yang $X$, Tsui HY: Cross-sectional and longitudinal factors predicting influenza vaccination in Hong Kong Chinese elderly aged 65 and above. J Infect 2008, 56:460-468.

46. Leung JCK: Effectiveness of influenza vaccination among elderly home residents in Hong Kong: a retrospective cohort study. Hong Kong Pract 2007, 29:123-133.
47. Centers for Disease Control and Prevention: Influenza vaccination coverage among children aged 6-23 months - United States, 2005-2006 influenza season. MMWR 2007, 56:959-963.

48. Shahrabani S, Benzion U, Yom DG: Factors affecting nurses' decision to get the flu vaccine. Eur J Health Econ 2009, 10:227-231.

49. Lyn-Cook R, Halm EA, Wisnivesky JP: Determinants of adherence to influenza vaccination among inner-city adults with persistent asthma. Prim Care Respir J 2007, 16:229-235.

50. Nexe J, Kragstrup J, Sgaard J: Decision on influenza vaccination among the elderly: a questionnaire study based on the health belief model and the multidimensional locus of control theory. Scand J Prim Health Care 1999, 17:105-110.

51. Henninger M, Naleway A, Crane B, Donahue J, Irving S: Predictors of seasonal influenza vaccination during pregnancy. Obstet Gynecol 2013, 121:741-749.

52. Department of Health: Department of Health Annual Report 2009/2010. Hong Kong: Department of Health.

53. Grant VJ, Le Saux N, Plint AC, et al: Factors influencing childhood influenza immunization. CMAJ 2003, 168:39-41.

54. Humiston SG, Lerner EB, Hepworth E, Blythe T, Goepp JG: Parent opinions about universal influenza vaccination for infants and toddlers. Arch Pediatr Adolesc Med 2005, 159:108-112.

55. Poehling KA, Speroff T, Dittus RS, Griffin MR, Hickson GB, Edwards KM: Predictors of influenza virus vaccination status in hospitalized children. Pediatrics 2001, 108:e99.

56. Mena G, Llupià A, García-Basteiro AL, Sequera VG, Aldea M, Bayas JM, Trilla A: Educating on professional habits: attitudes of medical students towards diverse strategies for promoting influenza vaccination and factors associated with the intention to get vaccinated. BMC Med Educ 2013, 13:99.

57. Suzuki SF, Sunagawa TF, Ohyama TF, Tanaka-Taya KF, Taniguchi KF, Okabe $\mathrm{N}$ : Evaluation of public knowledge about influenza based on influenza hotline consultations. Kansenshogaku Zasshi 2004, 78:99-107.

58. Lau AY, Sintchenko V, Crimmins J, Magrabi F, Gallego B, Coiera E: Protocol for a randomised controlled trial examining the impact of a web-based personally controlled health management system on the uptake of influenza vaccination rates. BMC Health Serv Res 2012, 2:12-86.

59. Lin C, Nowalk M, Zimmerman R, et al: Beliefs and attitudes about influenza immunization among parents of children with chronic medical conditions over a two-year period. J Urban Health 2006, 83:874-883.

60. Nowalk MP, Lin CJ, Zimmerman RK, et al: Changes in parents' perceptions of infant influenza vaccination over two years. J Natl Med Assoc 2007, 99:636-641.

61. Humiston SG, Szilagyi PG, Iwane MK, et al: The feasibility of universal influenza vaccination for infants and toddlers. Arch Pediatr Adolesc Med 2004, 158:867-874.

62. Ajzen I: The theory of planned behavior. Organ Behav Hum Decis Process 1991, 50(2):179-211.

63. Bozionelos $G$, Bennett $P$ : The theory of planned behaviour as predictor of exercise: the moderating influence of beliefs and personality variables. $J$ Health Psychol 1999, 4(4):517-529.

64. Hagger MS, Chatzisarantis NL, Barkoukis V, et al: Cross-cultural generalizability of the theory of planned behavior among young people in a physical activity context. J Sport Exercise Psy 2007, 29(1):1-20.

65. Kwan MY, Cairney J, Hay JA, Faught BE: Understanding physical activity and motivations for children with developmental coordination disorder: an investigation using the theory of planned behavior. Res Dev Disabil 2013, 34:3691-3698.

66. Liao Q, Cowling BJ, Lam WW, Fielding R: Factors affecting intention to receive and self-reported receipt of 2009 pandemic (H1N1) vaccine in Hong Kong: a longitudinal study. PLoS One 2011, 6(3):e17713.

67. Neuzil K-M, Jackson L-A, Nelson J, et al: Immunogenicity and reactogenicity of 1 versus 2 doses of trivalent inactivated influenza vaccine in vaccine-naive 5-8-year-old children. J Infect Dis 2006, 194:1032-1039.

68. Shuler $C M$, Iwamoto $M$, Bridges $C B$, et al: Vaccine effectiveness against medically attended, laboratory-confirmed influenza among children aged 6 to 59 months, 2003-2004. Pediatrics 2007, 119:e587-e595.

69. Lau JTF, Yang X, Tsui HY, Kim JH: Prevalence of influenza vaccination and associated factors among community-dwelling Hong Kong residents of age 65 or above. Vaccine 2006, 24:5526-5534. 
70. Fendrick AM, Monto AS, Nightengale B, Sarnes M: The economic burden of non-influenza-related viral respiratory tract infection in the United States. Arch Intern Med 2003, 163:487-494.

71. Lau JTF, Yu A, Cheung JCK, Leung SSF: Studies on common illnesses and medical care utilization patterns of adolescents in Hong Kong. J Adolesc Health 2000, 27:443-452.

72. Zimmerman RK, Raymund M, Janosky JE, Nowalk MP, Fine MJ: Sensitivity and specificity of patient self-report of influenza and pneumococcal polysaccharide vaccinations among elderly outpatients in diverse patient care strata. Vaccine 2003, 21:1486-1491

73. Smith PJ, Humiston SG, Marcuse EK, et al: Parental delay or refusal of vaccine doses, childhood vaccination coverage at 24 months of age, and the health belief model. Publ Health Rep 2011, 126(Suppl 2):135-146.

74. Chor JSY, Ngai KLK, Goggins WB, et al: Willingness of Hong Kong healthcare workers to accept pre-pandemic influenza vaccination at different WHO alert levels: two questionnaire surveys. BMJ 2009, 339:b3391.

doi:10.1186/1471-2458-13-1026

Cite this article as: Lau et al: Coverage and parental perceptions of influenza vaccination among parents of children aged 6 to 23 months in Hong Kong. BMC Public Health 2013 13:1026.

\section{Submit your next manuscript to BioMed Central and take full advantage of:}

- Convenient online submission

- Thorough peer review

- No space constraints or color figure charges

- Immediate publication on acceptance

- Inclusion in PubMed, CAS, Scopus and Google Scholar

- Research which is freely available for redistribution 